\title{
EVALUATION OF THE LONG-TERM EFFECTS OF EXPOSURE TO GREENSPACE ON TYPE 2 DIABETIC PATIENTS: CASE STUDY - TEHRAN, IRAN
}

\author{
Amin Esmaeilzadeh ${ }^{1}$, Mahmoud Reza Delavar ${ }^{2, *}$, Ensieh Nasli-Esfahani ${ }^{3}$ \\ ${ }^{1}$ MSc. student, GIS Dept., School of Surveying and Geospatial Engineering, College of Engineering, University of Tehran, Tehran, \\ Iran - esmaeilzade.amin@ut.ac.ir \\ ${ }^{2}$ Center of Excellence in Geomatic Eng. in Disaster Management, School of Surveying and Geospatial Eng., College of Engineering, \\ University of Tehran, Tehran, Iran - mdelavar@ut.ac.ir \\ ${ }^{3}$ Endocrinology and Metabolism Research Center, Endocrinology and Metabolism Clinical Sciences Institute, Tehran University of \\ Medical Sciences, Tehran, Iran - e-naslie@sina.tums.ac.ir
}

Commission IV, WG IV/3

KEY WORDS: Greenspace, Diabetes, GIS, NDVI, Long-term, Epidemiology, Spatial uncertainty assessment

\begin{abstract}
:
Development of information technology and expansion of geospatial information systems have realized the planning managers and urban policy-makers' wishes in making more informed decisions about urban management. At the same time, population growth and the provision of its health should be considered as one of the most important and remarkable issues for many researchers and medical specialists. So, in recent years there have been an increasing number of researches related to the study of effective factors such as environment parameters on the people's health. In previous research, the long-term exposure effects of environmental parameters such as greenspace and air pollution on people's health have been mostly ignored or access to reliable data has not been accomplished. The aim of this research is to study how the long-term exposure to greenspace surrounding the type 2 diabetes mellitus (T2DM) affects the average values of four years glycolized hemoglobin (HbA1c) levels. Moreover, in order to study the effects of the data type on reliability of the results, land-use data base (LDB) and satellite imagery have been employed. Pearson product and regression model have been used in this research for correlation and buffer analyse to calculate the degree of exposure of T2DM persons to greenspace. According to the results, negative correlation between long-term exposure to greenspace and the average values of four years HbAlc levels becomes statistically significant. Pearson correlation coefficients for the LDB ( $\mathrm{r}=-0.366$, $\mathrm{p}=0.001)$ and satellite imagery $(\mathrm{r}=-0.276, \mathrm{p}=0.006)$ at 250 -meter buffer from diabetic patients' habitat is significant at $99 \%$ confidence level.
\end{abstract}

\section{INTRODUCTION}

Following to the unpredicted urban growth, the need for the provision of appropriate society health and welfare remains as a main challenge which has directed researchers towards further investigation in order to consider the health of individuals specially patients. According to the International Diabetes Federation (IFD) report, in 2017 there were more than 450 million (age 18-99 years) people with diabetes worldwide. IFD was expected to increase to 693 million by 2045 (Cho et al. 2018).

Although the effect of genetic factors on diabetes, cardiovascular diseases and cancer is known, there are evidences suggesting the great importance of environmental factors (Willett 2002, Thayer et al. 2012). Attention to the urgency of this subject persuade researchers and medical specialists to discover clinical and environment factors affecting the health of diabetic patients type 2 in order to improve the health of the patients by knowing such factors.

In some results about the effectivity of greenspace environmental variables, air and sound pollution, traffic and height, there are evidences of a significant relation between the environmental parameters and the health of diabetic and cardiovascular patients (Teichert et al. 2013, Park et al. 2015, Pindus 2015, Bernabé-Ortiz et al. 2016). Since greenspace can increase physical activity and reduce surrounding stress as well as air pollution, it may have beneficial effects on people subject to sudden death risk like diabetic, cardiac and blood pressure patients (Wu et al. 2018). Living in supportive neighborhood environment for T2DM is indicated as the best location for health care (Astell-Burt et al. 2014). Additionally, three factors are correlated with greenspace and health including harm reduction (such as decreasing the exposure to air and sound pollution and heat), restoring capacities (such as physiological stress recovery) and structural capacities (like encouraging for undertaking physical activities and facilitating social cohesion) (Markevych et al. 2017). Wu et al. (2018) showed that with an increase of $1 \mathrm{~km} / \mathrm{km}^{2}$ in greenway and an increase of $10 \%$ in forests, the risk of sudden death such as diabetes, heart disease and hypertension have been reduced by $18 \%$ and $10 \%$, respectively (Wu et al. 2018). Moreover, Feng et al. (2014) shown that districts deprived of supportive neighborhood greenspace environments increase the risk of T2DM. Parks and other greenspaces cause the promotion of active life style and reduction of T2DM. $20 \%$ increase in the habitat surrounding green space causes a $1.1 \%$ reduction in the rate of $\mathrm{T} 2 \mathrm{DM}$ (Astell-Burt et al. 2014). The relationship of greenspace with overweight and outdoors physical activities is studied by Hoek et al. (2018). It has reminded that distance from the nearest park had no relation with overweight and outdoors physical activities, although surrounding greenspace relations with the aforementioned variables is non-linear (Klompmaker et al. 2018).

In previous research, the long-term effect of exposure to greenspace on T2DM has been ignored. The present study uses HbA1c levels, which reflects the average of serum glucose

\footnotetext{
* Corresponding author
} 
within about 3 months, for studying the long-term effect of exposure to greenspace in T2DM. In some of the previous research, approximate addresses of the patients (for example, the nearest intersection to their habitat) were used to explore the effect of exposure to greenspace. In present study we use the exact address of the patients' habitat in their analysis to avoid employing the approximate locational data which affects the accuracy and reliability of the results. The aim of this research is studying the long-term impact of greenspace surrounding the patients' habitat on their HbAlc levels, so that through proper urban planning the progress of fatal complications of this illness decrease. Moreover, two kinds of data namely, land-use data base (LDB) and satellite imagery are explored and compared in order to study the effect of locational data on the T2DM.

\section{METHODOLOGY}

\subsection{Correlation analysis}

Correlation analysis is a statistical method for studying the relationship between random variables. This correlation refers to the degree of linear relationship the two variables have. The correlation can be presented by correlation coefficient $r$ whose value is in the interval $[1,-1]$. The value of 1 and -1 are respectively the highest positive and negative relations. There are several kinds of prevailing methods for measuring the correlation level such as Pearson correlation product, Spearman's rank correlation and Kendall tau rank correlation (Li et al. 2017).

\subsubsection{Pearson correlation product}

Pearson correlation product is widely used for determining the correlation between two variables. This product shows the intensity and direction of the relationship as shown in Eq.1 (Park et al. 2015).

$$
r_{x y}=\frac{\sum_{\bar{i}=1}^{n}(x-\bar{x})}{\sqrt{\sum_{i=1}^{n}(x-\bar{x})^{2} \times(y-\bar{y})^{2}}}
$$

where,

$$
\begin{aligned}
& x=\text { random variable, } \\
& y=\text { random variable, } \\
& \bar{x}=\text { the expected walue of the random variable } x, \\
& \bar{y}=\text { the expected walue of the random variable } y, \\
& n=\text { the number of samples }
\end{aligned}
$$

\subsubsection{Linear regression model}

Linear regression models are used for estimating the relationship between two continuous independent and dependent variables which have normal distribution. The most prevalent confidence levels for the two-tailed test are taken to be $99 \%$ and $95 \%$ (Lee et al. 2017).

\subsection{Spatial analysis}

In a broad sense, spatial analysis is a type of analysis that uses locational analysis techniques to find and describe (or confirm their absence) patterns of human behaviour and express their spatial relationships with entities and events that have a spatial aspect. Geospatial information systems (GIS)-related operations such as geocoding and buffering techniques are used for spatial analysis (Nordbø, et al. 2018).

\subsubsection{Buffer}

In GIS, a buffer is a zone that is drawn around any point, line, or polygon that allows the users to uniformly examine features and other phenomena within equal distances.

\subsubsection{Exposure to greenspace}

Access to greenspace in epidemiological studies is typically possible using a Normalized Difference Vegetation Index (NDVI) or quantified land-use data base. Vegetation indices extracted from satellite images, measure the light reflected from the earth surface during photosynthesis activity based on that it is possible to calculate the vegetation density (James, Banay et al. 2015). Greenspace is defined as vegetation percent in statistical block group (Lee et al. 2017). Multiple measurable criteria of greenspace include mean pattern, land cover composition and roadside tree-plantings. Land cover composition criteria estimate the rate of the open space greenness which may cover environmental risks, stress reduction and promoting the healthy life style in the vicinity of local habitat (Baldauf 2017). Greenway density walking paths can be effective in enhancing the physical activity level and stress reduction (Wu et al. 2018). The classified land-use based on the greenspace in small geographical regions can be applied as the spatial data source to analyse the correlations (Astell-Burt et al. 2014).

\subsubsection{NDVI}

NDVI illustrates the green vegetation density by 30-meter spatial resolution extracted from Landsat images in this research. NDVI values are within the range of -1 and 1 that higher values indicate higher green vegetation density (Gamon et al. 2013). NDVI surrounding greenness, that is the average NDVI in a circular buffer of the habitat address of the participants, is used as a criterion for measuring the exposure to greenspace.

\subsubsection{Land-use data base of greenspace}

LDB which shows the greenspace land-use is also used for calculating the ratio of greenspace in a circular buffer from habitat address of the participant (Klompmaker et al. 2018).

\section{IMPLEMENTATION}

\subsection{Study area and employed data}

The area and data of T2DM in this study are described in sections 3.1.1 and 3.1.2, respectively.

\subsubsection{Area}

The study area in this research includes Tehran Districts 2, 3, 6, 7,11 , and 12 . These districts are placed in the geographical area $51^{\circ} 21^{\prime} 47^{\prime \prime} \mathrm{E}, 35^{\circ} 45^{\prime} 35^{\prime \prime} \mathrm{W}, 51^{\circ} 27^{\prime} 29^{\prime \prime} \mathrm{E}$ and $35^{\circ} 41^{\prime} 6^{\prime \prime} \mathrm{W}$ (Figure 1).

\subsubsection{Data employed}

T2DM diagnosis is possible through laboratory samplings the most evident of which is fasting blood sugar greater than or equal to $126 \mathrm{mg} / \mathrm{dL}$ or $\mathrm{HbA} 1 \mathrm{c}$ which reflects the average serum glucose during about three months is more than $6.5 \%$. Data used in this study are divided into two groups including attribute and spatial data. In attribute part, patients' vital signs 
data (including glycolyzed haemoglobin (HbA1c), fasting blood sugar, two-hour blood sugar, blood pressure), demographic (including age, gender, body mass index (BMI), educational status, employment, and marital status) and life style (including exercises and diet) have been collected from their registered medical cases in two Diabetes Clinic and Metabolic Diseases Centers of Endocrines \& Metabolism Research Institute during 2015 and 2018. In spatial data part, exact spatial locations of patients' habitat are collected through their medical cases and geocoded. Moreover, the greenspace data are provided through Tehran land-use data base and greenspace extracted from satellite imagery Landsat 8 on Nov 30, 2017 using NDVI. NDVI is derived from Landsat 8 satellite imagery which is available from The United States Geological Survey. In order to prepare the locational data of the greenspace surrounding the habitat of T2D patients, analysis tool of buffer neighbourhood in patient habitat with 250 and 500 meters radius are employed. The criterion of entrance to this Longitudinal and retrospective study is diabetic patients type 2 living in Tehran who have referred to Diabetes Clinic and Metabolic Diseases Centers of Endocrines \& Metabolism Research Institute are located in 1 and 4 Zones of Tehran 6 District. The attribute information of the follow-up patients is shown in Table 1 .

\begin{tabular}{|c|c|}
\hline Variables & Value \\
\hline \multicolumn{2}{|l|}{ Sociodemographics } \\
\hline Age (years, mean $\pm S D$ ) & $63.3 \pm 11.6$ \\
\hline \multicolumn{2}{|l|}{ Sex $(\%)$} \\
\hline Male & 45.4 \\
\hline Female & 54.6 \\
\hline \multicolumn{2}{|l|}{ Educational level (\%) } \\
\hline$<$ High school & 31.3 \\
\hline Diploma & 41.7 \\
\hline University graduate & 26.1 \\
\hline$>4$ years of College & 0.9 \\
\hline \multicolumn{2}{|l|}{ Greenspace $\left(\operatorname{Ln}\left(\mathrm{m}^{2}\right)\right.$, mean $\left.\pm \mathrm{SD}\right)$} \\
\hline LDB (250m buffer) & $5.4 \pm 4.1$ \\
\hline NDVI (250m buffer) & $8.4 \pm 1.2$ \\
\hline \multicolumn{2}{|l|}{ Adiposity and glycaemic measures } \\
\hline BMI $\left(\mathrm{kg} / \mathrm{m}^{2}\right.$, mean $\left.\pm \mathrm{SD}\right)$ & $28.7 \pm 5.4$ \\
\hline $\mathrm{HbA} 1 \mathrm{c}(\%$, mean $\pm \mathrm{SD})$ & $7.2 \pm 0.9$ \\
\hline Fasting glucose $(\mathrm{mg} / \mathrm{dL}$, mean $\pm \mathrm{SD})$ & $146.1 \pm 49.2$ \\
\hline \multicolumn{2}{|l|}{ Physical activity $(\%)$} \\
\hline No activity & 24.4 \\
\hline Walking (<3h/week) & 33.6 \\
\hline Walking (>3h/week) & 35.9 \\
\hline Exercise \& walking & 6.1 \\
\hline \multicolumn{2}{|c|}{$\begin{array}{l}\text { Abbreviations: SD, standard deviation; Ln, natural } \\
\text { logarithm; LDB, land-use data base; NDVI, normalized } \\
\text { difference vegetation index; BMI, body mass index; } \\
\text { HbA1c, glycosylated haemoglobin }(\%) \text {. }\end{array}$} \\
\hline
\end{tabular}

Table 1. Baseline characteristics of the Longitudinal study follow-up participants

\subsection{Preprocessing}

Preprocessing data stage includes two parts as determining the follow-up patients and removing the outliers. In the first part, patients who registered their vital signs continuously since March, 2015 until Sept. 2018 in their medical cases were separated from other patients. Therefore, among 377 patients monitored in this research, 141 patients got to the next stages of preprocessing as the follow-up patient. In the second part, 10 patients were known as the outlier because of their high body mass index, pre-diabetes, sever physical activity and the absence of any other rare disease history.

\section{RESULTS}

In Section 4.1, the results are related to the relationship between long-term exposure to greenspace and $\mathrm{HbA1c}$ using the two LDB and satellite imagery data. Also, in Section 4.2, the results of Section 4.1 are compared.

\subsection{Studying the correlation between greenspace and the value of glycolized hemoglobin (HbA1c)}

The results related to the relationship between greenspace and blood glucose are divided into two sections. In section 4.1.1, the relationship between greenspace and $\mathrm{HbA} 1 \mathrm{c}$ is investigated using LDB data. In section 4.1.2, the relationship between greenspace and $\mathrm{HbAlc}$ is investigated using the satellite image data.

\subsubsection{Land-use data of greenspace}

In this section, correlation between the patients' $\mathrm{HbAlc}$ values and greenspace surrounding their habitat is explored using the land-use data of greenspace via Pearson correlation analyses and linear regression. The statistical results of this study are presented in Tables 2 and 3.

As shown in Table 2, Pearson correlation product between the patients' HbA1c value and greenspace surrounding the 250meters buffer of their habitat is statistically significant at $99 \%$ confidence level $(r=-0.366$, $p$-value $=0.001)$. In addition, Pearson correlation product between patients' $\mathrm{HbA} 1 \mathrm{c}$ value and greenspace surrounding 500-meter buffer of their habitat is statistically significant at confidence level of $95 \%$ ( $r=-0.215$, pvalue $=0.017$ )

With regard to Table 3, Predictor coefficient of independent variable of greenspace surrounding the 250-meter buffer of patient habitat becomes statistically significant at $99 \%$ confidence level $(\mathrm{r}=-.138$, $\mathrm{p}$-value $=0.001)$. This significance indicates the negative relation between the patients' $\mathrm{HbAlc}$ values and the greenspace surrounding their habitat. Therefore, $13 \%$ increase in greenspace area surrounding the patient's habitat causes one unit reduction of HbA1c in T2DM.

Predictor coefficient of independent variable of greenspace surrounding the 500-meter buffer of patient habitat is statistically significant at $95 \%$ confidence level $(r=-0.168$, pvalue $=0.017$ ). This result indicates the negative relation between the patients' HbAlc values and the greenspace surrounding their habitat. Therefore, $16 \%$ increase in greenspace area surrounding the patient's habitat causes one unit reduction of $\mathrm{HbA} 1 \mathrm{c}$ in T2DM.

The results obtained from regression coefficients between 250 and 500-meter buffers, suggest the higher influencibility of the habitat from his/her surrounding greenspace. This higher influencibility on the patient health can be because of more willingness of the person towards doing physical activity and also the effect of greenspace on reducing the environmental pollutants near to the patient's habitat.

\subsubsection{Greenspace data extracted from satellite imagery}

In this section, the correlation between the patients' HbAlc values and greenspace surrounding their habitat is explored using the greenspace map extracted from NDVI via Pearson correlation analyses and linear regression. 

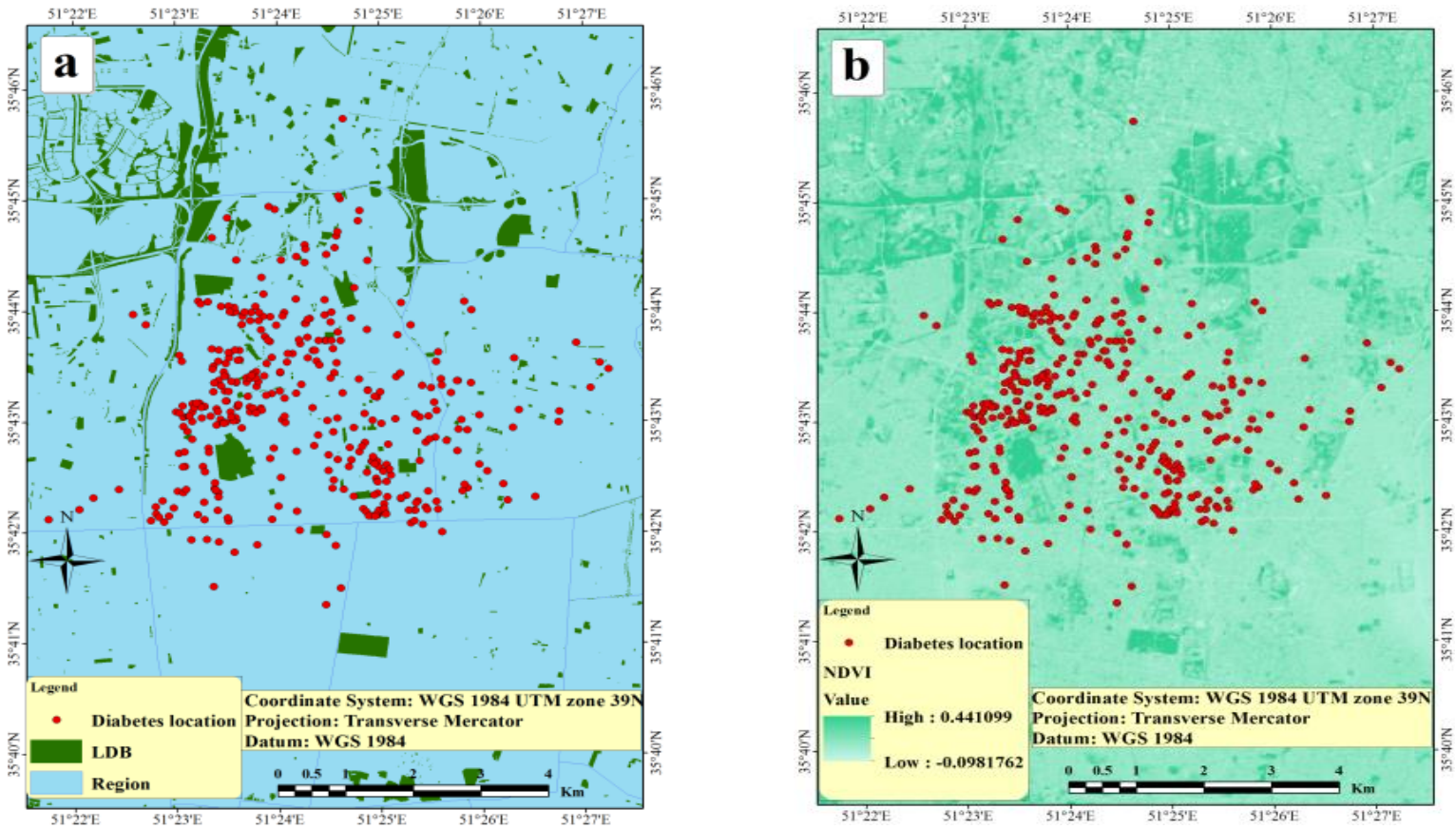

Figure 1. Distribution of T2DM in a) LDB and b) NDVI maps

\begin{tabular}{|c|c|c|c|c|c|}
\hline & & $\begin{array}{c}\text { LDB } \\
\text { 250-meters } \\
\text { buffer } \\
\end{array}$ & $\begin{array}{c}\text { LDB } \\
\text { 500-meters } \\
\text { buffer }\end{array}$ & $\begin{array}{c}\text { NDVI } \\
\text { 250-meters } \\
\text { buffer }\end{array}$ & $\begin{array}{c}\text { NDVI } \\
\text { 500-meters } \\
\text { buffer }\end{array}$ \\
\hline $\begin{array}{l}\text { Average } 4 \text { years } \mathrm{HbA} 1 \mathrm{c} \\
\text { Follow-up T2DM }\end{array}$ & $\begin{array}{c}\text { Pearson Correlation } \\
\text { Sig. (2-tailed) } \\
\text { N }\end{array}$ & $\begin{array}{c}-.366^{* *} \\
.001 \\
81\end{array}$ & $\begin{array}{r}-.215^{*} \\
.017 \\
124\end{array}$ & $\begin{array}{c}-.276^{* * *} \\
.006 \\
97\end{array}$ & $\begin{array}{r}-.195^{*} \\
.029 \\
126\end{array}$ \\
\hline
\end{tabular}

Table 2. Pearson correlation product

Given Table 2, Pearson correlation product between the patients' HbAlc value and greenspace surrounding the 250meter buffer of their habitat is statistically significant at $99 \%$ confidence level $(\mathrm{r}=-0.276$, $\mathrm{p}$-value=0.006). In addition, Pearson correlation product between patients' $\mathrm{HbA1c}$ value and greenspace surrounding 500-meter buffer of their habitat is statistically significant at confidence level of $95 \%(\mathrm{r}=-0.195, \mathrm{p}-$ value $=0.029$ ). With regard to Table 3 , predictor coefficient of independent variable of greenspace surrounding the 250-meter buffer of patient's habitat becomes statistically significant at $99 \%$ confidence level ( $r=-.180$, p-value $=0.006$ ). This result indicates the negative relationship between the patients' $\mathrm{HbA1c}$ values and the greenspace surrounding their habitat. Therefore, $18 \%$ increase in greenspace area surrounding the patient's habitat causes one unit reduction of HbA1c in T2DM. Predictor coefficient of independent variable of greenspace surrounding the 500-meter buffer of patient habitat is statistically significant at $95 \%$ confidence level $(r=-0.149, p$-value $=0.029)$. This result indicates the negative relation between the patients' $\mathrm{HbAlc}$ values and the greenspace surrounding their habitat. Therefore, $14 \%$ increase in greenspace area surrounding the patient's habitat causes one unit reduction of HbA1c in T2DM.
Like previous section, the results obtained from the regression coefficients between 250 and 500-meter buffers show the higher influencibility of habitat distance from their surrounding greenspace. This higher influencibility on the patient health can be because of more willingness of the persons towards doing physical activities and also the effect of greenspace on reducing the environmental pollutants near to the patients habitat. In order to test the assumption that the distance between the greenspace and the location of the patients affects the type of physical activity of the patient, a test has been applied which its results are shown in Table 4. According to Table 4, increasing the distance from the green space (reducing the vegetation around the patient's residence) reduces physical activity which confirms our assumption.

\subsection{Comparing the results of land-use data and satellite imagery}

The results obtained in the last two sections indicate the more importance of land-use type (namely greenspace, park and garden) compared to vegetation in determining the effect of greenspace surrounding the patient habitat on HbA1c in T2DM. 


\begin{tabular}{|c|c|c|c|c|c|c|c|c|c|}
\hline & \multirow[t]{2}{*}{ Model } & \multicolumn{2}{|c|}{$\begin{array}{c}\text { Non-standardized } \\
\text { Coefficients }\end{array}$} & \multirow{2}{*}{$\begin{array}{c}\text { Standardize } \\
\mathrm{d} \\
\text { Coefficients } \\
\text { Beta } \\
\end{array}$} & \multicolumn{2}{|c|}{$95 \%$ Confidence Interval for B } & \multirow[t]{2}{*}{$\mathrm{R}$} & \multirow[t]{2}{*}{$\begin{array}{c}\mathrm{R} \\
\text { Square }\end{array}$} & \multirow[t]{2}{*}{ Sig. } \\
\hline & & $\mathrm{B}$ & Std. Error & & Lower Bound & Upper Bound & & & \\
\hline & (Constant) & 8.158 & 0.323 & & 7.514 & 8.802 & & & .000 \\
\hline 1 & $\begin{array}{c}\text { LDB } \\
\text { 250-meters buffer }\end{array}$ & -.138 & 0.040 & -.366 & -0.216 & -0.059 & $0.366^{\mathrm{a}}$ & 0.134 & .001 \\
\hline & (Constant) & 8.863 & 0.673 & & 7.530 & 10.195 & & & .000 \\
\hline 2 & $\begin{array}{c}\text { LDB } \\
\text { 500-meters buffer }\end{array}$ & -.168 & 0.069 & -.215 & -0.305 & -0.031 & $0.215^{\mathrm{b}}$ & 0.046 & .017 \\
\hline & (Constant) & 8.737 & 0.550 & & 7.645 & 9.828 & & & .000 \\
\hline 3 & $\begin{array}{l}\text { NDVI } \\
\text { 250-meters buffer }\end{array}$ & -.180 & 0.065 & -.276 & -0.308 & -0.052 & $0.276^{\mathrm{c}}$ & 0.076 & .006 \\
\hline & (Constant) & 8.745 & 0.706 & & 7.347 & 10.142 & & & .000 \\
\hline 4 & $\begin{array}{c}\text { NDVI } \\
\text { 500-meters buffer }\end{array}$ & -.149 & 0.067 & -0.195 & -0.281 & -0.015 & $0.195^{\mathrm{d}}$ & 0.038 & .029 \\
\hline & $\begin{array}{l}\text { endent Variable: Av } \\
\text { redictors: (Constant) } \\
\text { redictors: (Constant } \\
\text { redictors: (Constant) } \\
\text { redictors: (Constant } \\
\text { oefficient of correla }\end{array}$ & $\begin{array}{l}\text { ge } 4 \text { ye } \\
\text { DB }(25 \\
\text { DB }(50 \\
\text { JDVI }(2 \\
\text { JDVI }(5 \\
\text {; R Squ }\end{array}$ & $\begin{array}{l}\text { HbAlc Fol } \\
\text { heters buffe } \\
\text { heters buffe } \\
\text { meters buff } \\
\text { meters buff } \\
\text { : coefficien }\end{array}$ & Ip patients & & & & & \\
\hline
\end{tabular}

Table 3. Linear regression models

This predisposition is because of the high susceptibility of satellite imagery to vegetation cover and no persuading effect of vegetation on the patient to do physical activities.

\begin{tabular}{|c|c|c|}
\hline Physical activity per week & $\begin{array}{c}\text { Greenspace } \\
\left(\mathrm{Ln}\left(\mathrm{m}^{2}\right), \text { mean } \pm \mathrm{SD}\right)\end{array}$ & $\mathrm{N}$ \\
\hline No activity & $4.47 \pm 4.15$ & 29 \\
Walking (less than 3 hours) & $4.37 \pm 4.42$ & 39 \\
Walking (more than 3 hours) & $5.78 \pm 3.87$ & 42 \\
walking and exercise & $7.18 \pm 3.59$ & 7 \\
Total & $5.07 \pm 4.15$ & 117 \\
\hline
\end{tabular}

Abbreviations: SD, standard deviation; Ln, natural logarithm; $\mathrm{N}$, the number of T2DM

Table 4. Comparing means of greenspace in physical activity groups in follow-up T2DM

\subsection{The spatial uncertainty assessment}

The uncertainty in the detection of greenspace using the NDVI index was one the ambiguous spatial data sources in this study. In order to investigate the effect of this kind of uncertainty on prediction results, two linear regression models were used. In the first and second models, the NDVI index was considered to be $0.08-0.44$ and $0.1-0.44$ for greenspace extraction, respectively (i.e., $25 \%$ increase in sensitivity to the NDVI index in the second model). The results of this analyse are presented in Table 5. According to Table 5, the greater value of the adjusted $\mathrm{R}$ square of the second model, compared to the first model, indicates an improvement in the explanation of the dependent variable (HbAlc) variations with respect to the predictor variable in the model. Therefore, uncertainty in determining the greenspace arising from NDVI could affect the analysis output. Also, according to the results of Table 5, the more sensitive the index is, the better estimation model will be in predicting the outcome variable.

\section{DISCUSSION AND CONCLUSION}

In the present study two aims were considered. The first was studying the type and the value of correlation coefficient between the long-term exposure to greenspace surrounding the T2DM habitat and the average of four years HbA1c levels at 250 and 500-meter buffers and the second was comparing the results obtained using the two data types, namely LDB and satellite imagery.

The results obtained from the first aim, suggest a negative and significant relationship between these two variables at confidence levels of $99 \%$ (for 250 -meter buffer) and $95 \%$ (for 500 -meter buffer). The results related to 250 -meter buffer have a higher reliability comparing to those of 500-meter buffer. Therefore, the improvement of blood glucose control in type 2 diabetic patients in the face of green space can be achieved through reduction of environmental risk factors (e.g. the reduction of air and noise pollution, heat and stress) and the easier accessibility of T2DM to equipment (e.g. increasing the sport activities and social interactions). Following the results obtained from the second aim, LDB is placed in higher reliability compared to satellite imagery which may be as the result of high susceptibility of satellite imagery to any kind of 


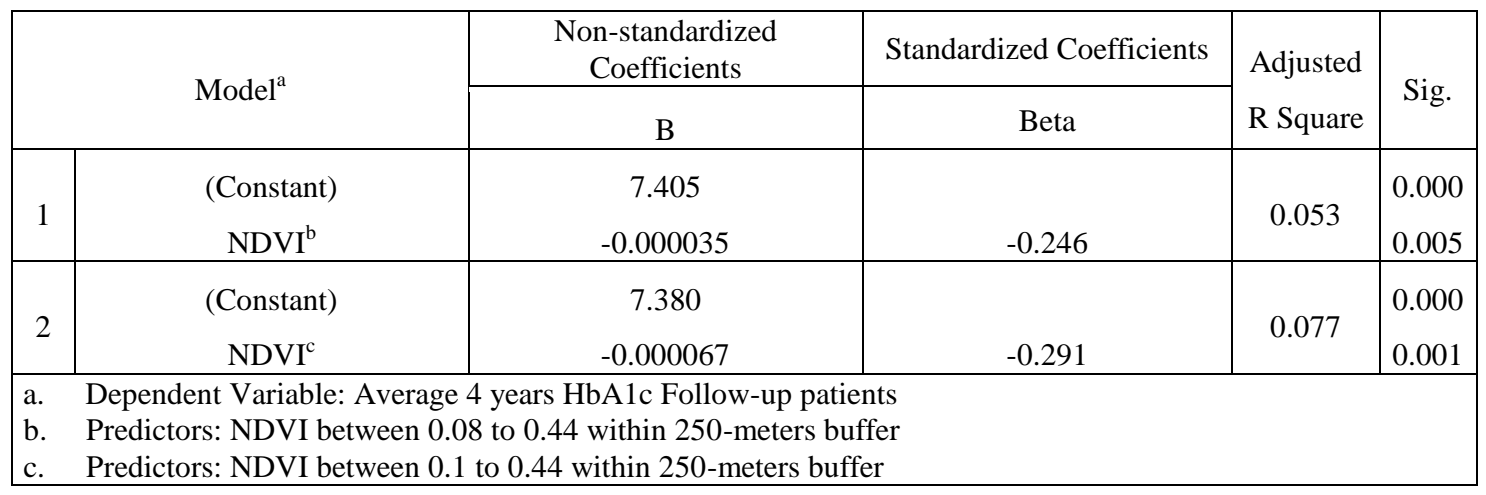

Table 5. Comparison of regression models using two different NDVI indices

vegetation cover, although this susceptibility cannot encourage the patient to do sport activities, it is the land-use data type (for example park and garden) that enhances the patient willingness to do physical activities.

Generally, the results obtained in the study confirmed the results of previous works while the long-term effect of exposure to greenspace is also evaluated in the present study. Due to the increasing of aging rate and the prevalence of type 2 diabetes and according to the positive impact of the greenspace parameter studied in this research, related to the improvement of blood glucose control, greenspace can be considered as an important parameter in urban planning for the expansion of cities and creating recreational greenspaces and parks. This issue is especially important in metropolitan cities and high populated cities which suffer from traffic and air pollution problems.

Additionally, the results of this study reflect the uncertainty caused by the NDVI index in the extraction of greenspace from satellite imagery in the prediction outcomes of a model based on the effect of long-term exposure to greenspace around the residence of type 2 diabetic patients on controlling their blood sugar.

Among the limitations of this study is the lack of a large number of T2DM data to achieve a higher reliability and nonavailability of up to date LDB. It is suggested to use more samples in future research in order to enhance the reliability of the results. Another limitation of our study is inaccessibility to patients' socio-economic data. Although the spatial distribution of patients (Figure 1) is so that they have relatively the same socio-economic situation, its impact can be considered as an intermediate risk factor in future studies.

\section{Acknowledgements}

The authors would like to thank two Diabetes Clinic and Metabolic Diseases Centers of Endocrines \& Metabolism Research Institute, Tehran, Iran for providing the data and VicePresident for Research, University of Tehran to fund the research.

\section{References}

Astell-Burt, T., Feng, X., Kolt, G. S. Is neighborhood green space associated with a lower risk of type 2 diabetes? Evidence from 267,072 Australians. Journal of Diabetes care, 2014, 37(1): 197-201.

Baldauf, R. Roadside vegetation design characteristics that can improve local, near-road air quality. Journal of Transportation Research Part(Transport Environment), 2017, 52: 354-361.
Bernabé-Ortiz, A., Carrillo-Larco, R. M., Gilman, R. H., Miele, C. H., Checkley, W., Wells, J. C., Smeeth, L., Miranda, J. J. Geographical variation in the progression of type 2 diabetes in Peru: The CRONICAS Cohort Study. Journal of diabetes research, 2016, 121: 135-145.

Brownson, R. C., Hoehner, C. M., Day, K., Forsyth, A., Sallis, J. F. Measuring the built environment for physical activity: state of the science. American Journal of Preventive Medicine, 2009, 36(4): S99-S123. e112.

Cho, NH., Shaw, JE., Karuranga, S., Huang, Y., da Rocha Fernandes, JD., Ohlrogge, AW., Malanda, B. IDF Diabetes Atlas: global estimates of diabetes prevalence for 2017 and projections for 2045. Journal of Diabetes Research Clinical Practice, 2018, 138: 271-281.

Gamon, J. A., Huemmrich, K. F., Stone, R. S., Tweedie, C. E. Spatial and temporal variation in primary productivity (NDVI) of coastal Alaskan tundra: Decreased vegetation growth following earlier snowmelt. Journal of Remote Sensing of Environment, 2013, 129: 144-153.

James, P., Banay, R. F., Hart, J. E., Laden, F. A review of the health benefits of greenness. Journal of Current Epidemiology Reports, 2015, 2(2): 131-142.

Klompmaker, J. O., Hoek, G., Bloemsma, L. D., Gehring, U., Strak, M., Wijga, A. H., van den Brink, C., Brunekreef, B., Lebret, E., Janssen, N. AH. Green space definition affects associations of green space with overweight and physical activity. Journal of Environmental Research, 2018, 160: 531540.

Lee, J., Hwang, S-J., Mutalik, K., Corey, D., Joyce, R., Block, JP., Fox, CS., Powell-Wiley, TM. Association of built environment characteristics with adiposity and glycaemic measures. Journal of Obesity Science, 2017, 3(3): 333-341.

Li, X., Tu, W., Shaoqing, S., Yang, Y., Luo, N., Li, Q. Revealing spatial variation and correlation of urban travels from big trajectory data. ISPRS-Int. Arch. Photogramm., Remote Sens. Spatial Inf. Sci., 2017, 42: 53-57.

Markevych, I., Schoierer, J., Hartig, T., Chudnovsky, A., Hystad, P., Dzhambov, A., De Vries, S., Triguero-Mas, M., Brauer, M., Nieuwenhuijsen, M. Exploring pathways linking greenspace to health: Theoretical and Methodological Guidance. Journal of Environmental Research, 2017, 158: 301317. 
Nordbø, E. C. A., Nordh, H., Raanaas, R. K., Aamodt, G. GISderived measures of the built environment determinants of mental health and activity participation in childhood and adolescence: A systematic review. Journal of Landscape and Urban Planning, 2018, 177: 19-37.

Park, S. K., Adar, S. D., O'Neill, M. S., Auchincloss, A. H., Szpiro, A., Bertoni, A. G., Navas-Acien, A., Kaufman, J. D., Diez-Roux, A. V. Long-term exposure to air pollution and type 2 diabetes mellitus in a multiethnic cohort. American Journal of Epidemiology, 2015, 181(5): 327-336.

Pindus, M., Orru, H., Modig, L. Close proximity to busy roads increases the prevalence and onset of cardiac disease-Results from RHINE Tartu. Journal of Public Health, 2015, 129(10): 1398-1405.

Teichert, T., Vossoughi, M., Vierkötter, A., Sugiri, D., Schikowski, T., Schulte, T., Roden, M., Luckhaus, C., Herder, C., Krämer, U. Association between traffic-related air pollution, subclinical inflammation and impaired glucose metabolism: results from the SALIA study. Journal of PLoS One, 2013, 8(12): e83042.

Thayer, K. A., Heindel, J., Bucher, J., Gallo, M. A. Role of environmental chemicals in diabetes and obesity: a National Toxicology Program workshop review. Journal of Environmental Health Perspectives, 2012, 120(6): 779-789.

Willett, W. C. Balancing life-style and genomics research for disease prevention. Journal of Science, 2002, 296(5568): 695698.

Wu, J., Rappazzo, K. M., Simpson, R. J., Joodi, G., Pursell, I. W., Mounsey, J P., Cascio, W. E., Jackson, L. E. Exploring links between greenspace and sudden unexpected death: a spatial analysis. Journal of Environment International, 2018, 113: 114-121. 